\title{
Congenital vertebral anomalies: aetiology and relationship to spina bifida cystica*
}

\author{
RUTH WYNNE-DAVIES \\ From the Department of Orthopaedic Surgery (Clinical Genetics Research), University of Edinburgh \\ Summary. A family survey of 337 patients with congenital vertebral anomalies \\ has been carried out from the Scoliosis Clinics of Edinburgh and the Royal National \\ Orthopaedic Hospital, London. \\ From genetic and epidemiological evidence it is clear that multiple vertebral an- \\ omalies (without apparent spina bifida) are aetiologically related to anencephaly and \\ spina bifida cystica, carrying a 5-10\% risk to subsequent sibs for any one of these \\ defects. The implications for prenatal diagnosis are discussed. \\ Solitary hemivertebrae and localized anterior defects of the vertebral bodies caus- \\ ing kyphoscoliosis are sporadic (non-familial) in nature, carrying no risk to subse- \\ quent sibs.
}

Developmental errors of vertebrae are extremely variable, involving anything from one level only to multiple defects throughout the length of the spine and affecting any part of the vertebrae. Clinical data relating to these defects and to congenital scoliosis and kyphoscoliosis have been reported by James (1955; 1967), MacEwen (1967), Winter et al (1968; 1973), and MacEwen et al (1972). Groups of anomalies based on anatomical types can be described and the following is taken mainly from James (1967).

1. Neural arch defects. Posterior arch defects may be partial or total, occur with or without a meningocele or myelomeningocele, and may be accompanied by vertebral body defects at any level of the spine (Fig. 1). Diastematomyelia may be present and lead to paraplegia as the child grows (Fig. 2). Scoliosis does not usually develop with the simple neural arch defects.

2. Segmental defects of the vertebral bodies. These vary from a single hemivertebrae (Fig. 3) to multiple defects over the whole length of the spine. Scoliosis is frequent, due to asymmetry of affected vertebrae and to their continued unequal growth. Spinal curvature (Figs. 2 and 4) may be apparent at

\footnotetext{
Received 24 July 1974.

* This paper is the subject of part of a PhD Thesis (Wynne-Davies, 1973), University of Edinburgh.
}

birth, develop during growth, or perhaps never develop at all if the segmental defects on each side of the vertebral column 'balance out'. Sprengel's shoulder and absence or fusion of ribs are common. Anomalous vertebrae tend to fuse during growth and a rigid bar of bone may develop on the concave side of a curve, giving rise to a particularly intractable form of scoliosis (Fig. 5).

These defects are not only of cosmetic significance: spinal curvature may be severe and rapidly developing, leading to cor pulmonale and perhaps paraplegia-although this latter is more common when diastematomyelia is present, and in the next group of anterior vetebral body defects.

3. Anterior vertebral body defects. The deformity resulting from anterior defects of the vertebral bodies is kyphoscoliosis-the term being used precisely to mean a true kyphosis as well as a lateral curvature of the spine (James, 1955; Winter et al, 1973). There may be partial or complete absence of one vertebral body (Fig. 6), fusion of two or three (Fig. 7), or a combination of these. It is characteristically a localized deformity extending only over one, two, or three vertebrae and the neural arch is usually unaffected. It is a potentially serious anomaly because the increasing angulation of the vertebrae as the child grows causes pressure on the spinal cord and paraplegia may develop. 

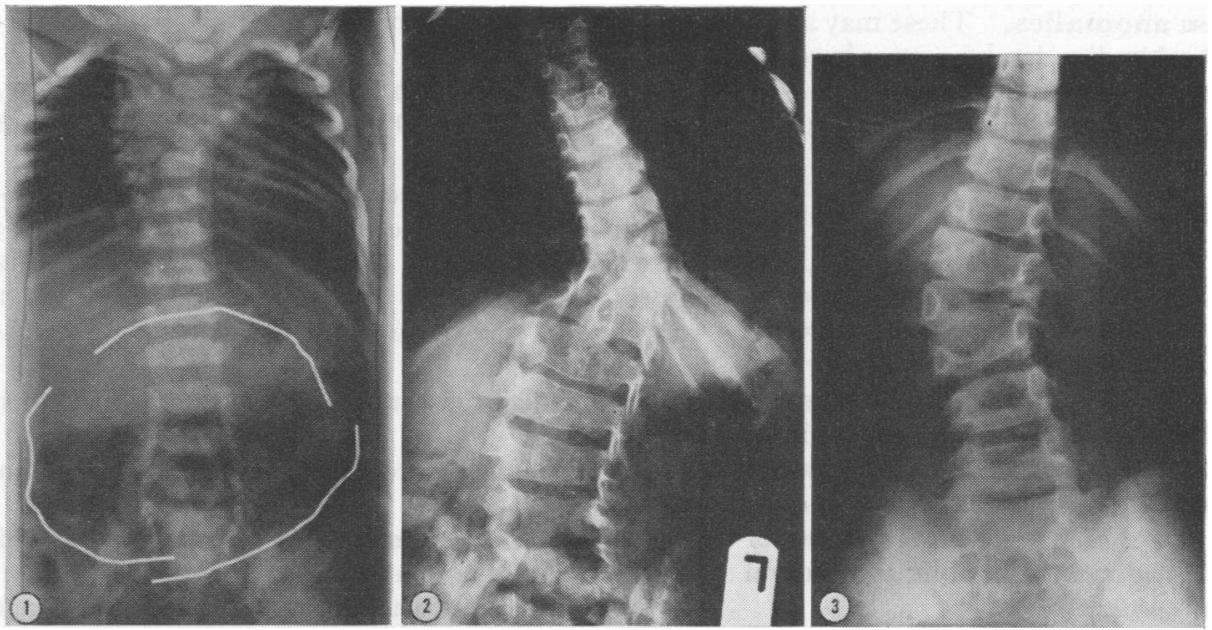
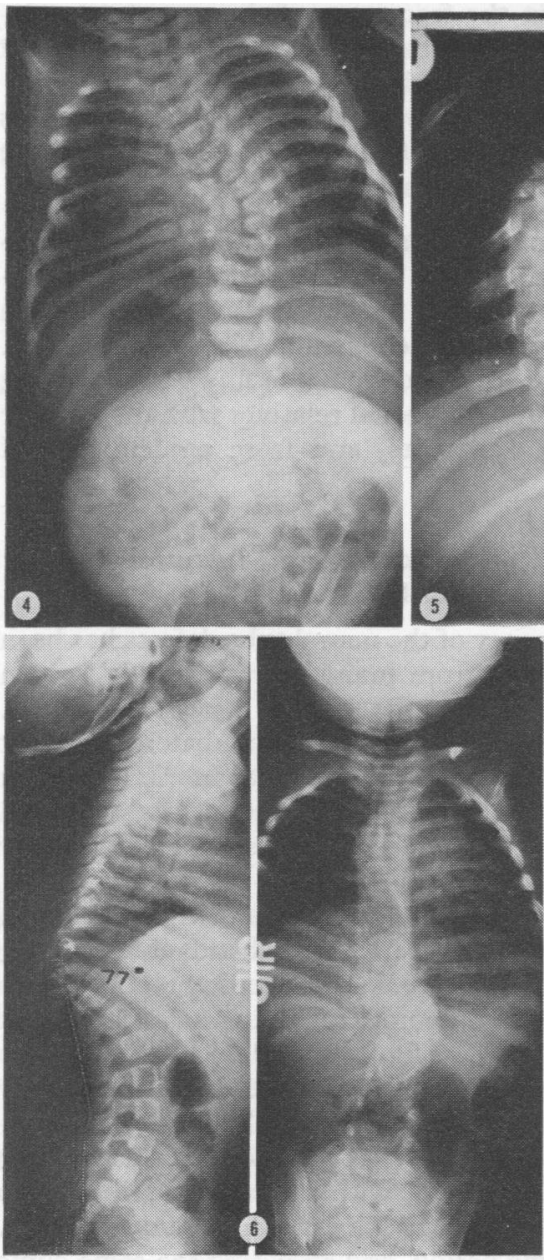
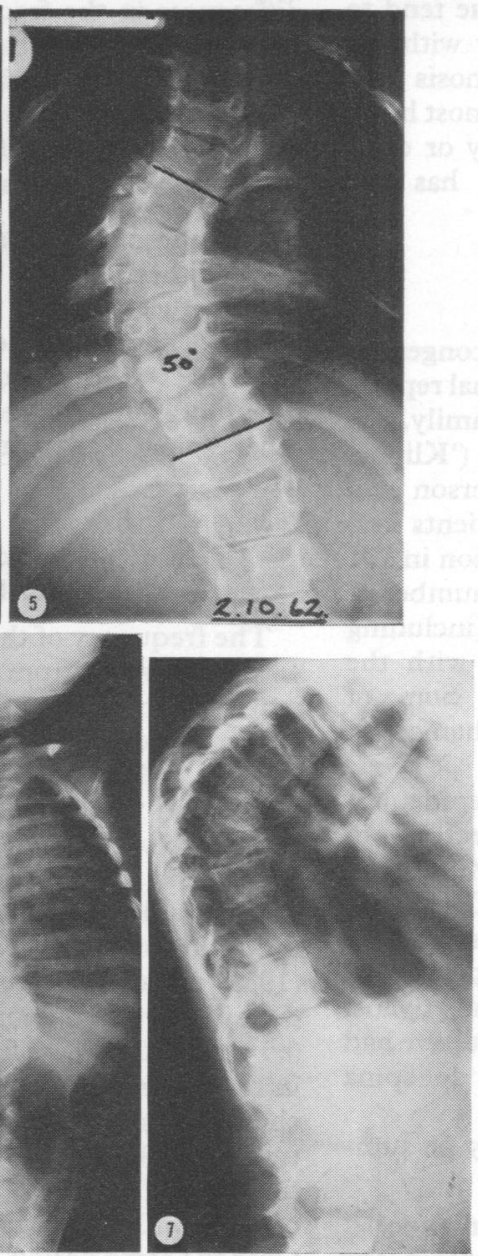

FIg. 1. A wide neural arch defect in the lumbar region and multiple segmental defects in the upper thoracic spine.

Fig. 2. The neural arch defect in the lumbar region is accompanied by diastematomyelia at the thoracolumbar junction, and anomalous (now fused) vertebrae immediately above.

Fig. 3. A simple hemivertebra at the second lumbar level.

Fig. 4. Multiple segmental defects in the midthoracic region of this infant, including fused ribs. Scoliosis is already developing. The type and extent of the anomalies is very clear in this early radiograph.

Fig. 5. In contrast with Figs. 1 and 4, this radiograph shows a $7 \frac{1}{2}$-year-old child with a fused mass of bone and a rigid bar on the concave side of the curve. Rib anomalies are present, but no very detailed radiographic diagnosis can be made at this stage.

FIG. 6. A lateral radiograph of the spine of a oneyear-old girl showing an absent vertebral body in the lower thoracic region. Already there is an acute kyphosis and paraplegia is likely to develop as she grows. The antero-posterior radiograph at the same age is shown on the right. There is very little associated scoliosis.

Fig. 7. A lateral radiograph of the spine shows failure of development and fusion of three thoracic. vertebrae, with associated kyphosis. 
4. Minor fusion anomalies. These may affect two or more vertebral bodies, laminae, or spines and may occur with other segmental defects or as isolated features in an almost normal vertebral column.

\section{Difficulties of an exact radiological diagnosis}

The extreme variability of segmental vertebral defects defies classification and sometimes description. The problem is further increased by deformity of the spine (scoliosis and kyphosis) obscuring radiological detail. Lateral curvature will be accompanied by rotation of vertebrae, and so when taking an apparently antero-posterior view, the result may be, for example, a true antero-posterior view of the thoracic region with an oblique or lateral view of the lumbar spine.

As the child grows, anomalous vertebrae tend to fuse into a solid mass, and this, together with the spinal curvature may make exact diagnosis impossible in the older child or adult. The most helpful radiographs are those taken in infancy or early childhood, before significant deformity has developed or fusion occurred.

\section{Previous surveys}

There have been no family studies in congenital scoliosis, although there have been occasional reports of more than one affected member of a family. A family survey of cervical vertebral defects ('Klippel Feil syndrome') was carried out by Gunderson et al (1967). They investigated 11 index patients and carried out radiography of the cervical region in 121 relatives. They concluded there were a number of different genetic patterns of inheritance (including dominant and recessive types), varying with the nature of the lesion in the index patient. Some of their cases had vertebral anomalies other than cervical.

There have been many genetic and epidemiological studies of the neural tube defects from different parts of the world (Record and McKeown, 1950; Edwards, 1958; Williamson, 1965; Carter and Fraser Roberts, 1967; Naggan and MacMahon, 1967; Carter et al, 1968; Elwood, 1970; Fedrick, 1970; Richards et al, 1972; Carter and Evans, $1973 a$; 1973b). Some index patients must have had congenital vertebral defects in addition to spina bifida but how many is not known.

The main findings of these surveys may be summarized as follows:

(1) Anencephaly and spina bifida/meningocele, with or without hydrocephalus occur within the same kindreds and are therefore aetiologically related.

(2) Concordance in monozygous twins is low, perhaps only about $20 \%$ of co-twins of patients are affected.

(3) The risk of a second sib being affected is approximately $5 \%$ (higher in areas of high incidence); if two sibs are already affected, the risk to a third is approximately $10 \%$. The risk to children of adult survivors on the three small series available is approximately $3 \%$.

(4) The disorders are more common in the lower social classes.

(5) Some surveys report increased frequency in the winter months.

(6) There is an excess of first born children, and of mothers who are older than average.

(7) Within the British Isles there are regional differences in the frequency of the neural tube defects, being highest in Northern Ireland and lowest in south-east England.

The genetic liability to neural tube defects is thought to be polygenic acting together with a strong environmental element.

The aim of the current survey was to try and establish whether there was any aetiological relationship between spina bifida cystica, spina bifida occulta, and other congenital vertebral defects. Evidence was obtained from a family survey, noting the proportions of affected relatives with the same or other spinal anomalies, and from epidemiological data.

\section{Population incidence and frequency of spina bifida occulta}

The frequency of the neural tube defects has been well established from many surveys and in Britain ranges from approximately 3 to 8 per 1000 births. These defects, however, are immediately apparent at birth. There is more difficulty in establishing a population frequency for other congenital vertebral anomalies which may not be discovered for many years, or in some cases not at all.

In a study of 15000 minifilms of the chest from the State of Delaware, USA, Shands and Eisberg (1955) noted seven cases of congenital scoliosis with definite vertebral anomalies, giving an incidence of 0.5 per 1000 . This figure would exclude anomalies in the lower lumbar region, since they studied only chest $x$-rays. In the Edinburgh Scoliosis Clinic between 1958 and 1968 (the period of this survey) there were 72 patients with congenital scoliosis who came from Edinburgh City, the Lothians, and Fife. Over the same period, and attending the same clinic 
from the same area, there were 118 patients with idiopathic scoliosis. That is, idiopathic scoliosis was 1.6 times more common. The external deformity is similar and ascertainment for the two is likely to be comparable. The general population incidence for idiopathic scoliosis has been established in Edinburgh as approximately 2 per 1000 (Wynne-Davies, 1968) and so a figure of 1 per 1000 for congenital vertebral anomalies is a reasonable guess; it is not too dissimilar from Shands' and Eisberg's figure (1955) which is clearly too low an estimate.

The frequency of very minor vertebral anomalies is impossible to assess since there will be no reason for individuals to attend hospital for treatment, and even if radiographs were taken of a large population, only some of such defects would be apparent.

An investigation was carried out in Edinburgh to determine the frequency of spina bifida occulta at the 5 th lumbar/1st sacral level. It was thought to be very common in the general population and it was hoped to assess the significance of relatives who might be so affected. Lorber and Levick (1967) noted $20 \%$ of parents with spina bifida occulta and only $5 \%$ of controls-though some anatomy text books refer to $5-10 \%$. In view of the uncertainty of seeing this minor anomaly on any one radiograph, a series was examined of 162 patients with idiopathic scoliosis and 59 with paralytic scoliosis due to previous poliomyelitis. These two groups were chosen because each individual had dozens of vertebral column radiographs taken at intervals throughout the growing period-perhaps from 3 months to 16 years of age. There was, therefore, a greater chance of observing this minor vertebral anomaly. Results indicated that at least half this population up to the age of 16 years (109 of 221 patients) had spina bifida occulta at the 5 th lumbar/1st sacral level, which must still be a minimum figure since this was only a radiographic survey.

The reason for failure to observe a minor neural arch defect on any one $x$-ray is that the two sides of the arch instead of meeting and fusing, over-ride one another (Fig. 8) and it will not necessarily be apparent on any one radiograph that a defect is present. In view of these figures, spina bifida occulta at the 5 th lumbar/1st sacral level has been ignored both in index patients and their relatives.

\section{Material and methods}

Three hundred and thirty-seven patients with vertebral anomalies were traced from two scoliosis clinics; 127 from the Edinburgh Clinic (1958-68) and 210 from the Royal National Orthopaedic Hospital, London (194868). No patient was included without adequate radio-

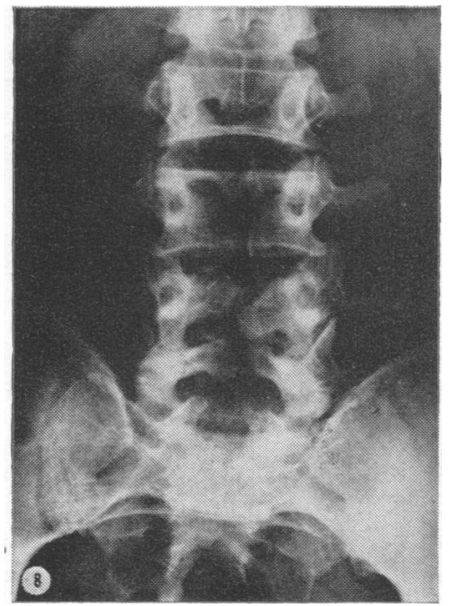

FIG. 8. Spina bifida occulta is apparent in the lower lumbar and sacral spine: the two halves of the neural arch of the fourth lumbar vertebra are tending to over-ride one another.

graphs, usually taken in early childhood, allowing as accurate a diagnosis as possible.

Congenital vertebral defects excluded from the survey were spina bifida cystica as a solitary defect (ie, unaccompanied by other vertebral anomalies); the Klippel Feil syndrome (although a number of patients were included with vertebral anomalies extending from the upper thoracic region into the neck); and anomalies of segmentation and spina bifida occulta at the lumbo-sacral junction.

The method of research was by family survey, noting particularly the proportions of anencephaly, spina bifida cystica, and other vertebral anomalies amongst relatives of index patients, and comparing this figure with the general population frequency. The homes of all 337 index patients were visited, a total of 924 first-degree relatives seen, and a history taken for relatives of secondand third-degree. Living relatives with clinical evidence of a vertebral anomaly where possible were brought to hospital for further examination and radiography. In all cases medical records, including necropsy reports, were sought; hearsay evidence of abnormality was not accepted.

The parents of the first 24 Edinburgh patients indexed (48 individuals) had routine radiographic examination of the vertebral column, but results being entirely negative it was thought unjustifiable to proceed with this investigation further. It is possible there are more relatives with minor defects than are reported here, but radiographic examination would not be a complete answer since minor vertebral anomalies might not be visible even if the quality of the radiographs were good. The only certain method of diagnosis is by direct vision, either during an operative procedure, or at necropsy. Major vertebral anomalies are nearly always clinically apparent, anencephaly and spina bifida cystica, of course, always so. 
Epidemiological data was collected relating to the pregnancy and birth history, parental age, parity, season of birth, social class, and regional distribution of index patients. Figures were compared with those obtained from the Annual Reports of the Registrar General and the Edinburgh Register of the Newborn, 1964-68* (a city register of all births with congenital anomalies, and a control series over the same period of 692 normal births, this latter data is used here).

\section{Results}

The 337 index patients were divided into four groups.

1. Spina bifida cystica group ( 39 patients). All had vertebral body anomalies in addition to the neural arch defect.

2. Spina bifida occulta group (79 patients). All had vertebral body anomalies in addition to a neural arch defect ( 39 had wide, extensive spina bifida but no meningocele and 40 had minor spina bifida occulta other than at the 5th lumbar/1st sacral level).

3. Multiple vertebral body anomalies group (118 patients) with no apparent neural arch defect.

4. Solitary vertebral body anomalies group (101 patients; 45 with isolated hemivertebrae, 40 with an anterior body defect and kyphoscoliosis, and 16 with minor anomalies such as narrowing of disc spaces or fused vertebrae only).

Group 3 is the least satisfactory in that it is possible a few patients in reality belong to group 2 . Anomalous vertebrae frequently fuse together as the child grows, and also unequal vertebral growth leads to their rotation-thus a minor defect of the neural arch may never be seen on a radiograph. However, the group as a whole is dissimilar to group 2 , and is quite clearly delineated both clinically and radiographically from group 4.

Results were noted separately for the Edinburgh and London clinics in view of the known regional differences in frequency.

Sex ratio. Females were more common in all groups. The male/female sex ratio was: for spina bifida (groups 1 and 2) 0.37; for multiple vertebral anomalies (group 3) 0.31 ; and for solitary vertebral anomalies (group 4) 0.68 .

Associated anomalies. Developmental anomalies unrelated to the axial skeleton and spinal cord defect were numerous, but showed no particular pattern. Appproximately $8 \%$ of the index patients

\footnotetext{
* Held at the Department of Social Medicine, University of Edinburgh.
}

in the spina bifida groups had associated anomalies and $16 \%$ of the index patients in the other two groups; this is far higher than would be expected from a random survey of the population $(2-3 \%)$.

\section{Genetic data $\nmid$}

Twins. All twins in all three groups were discordant (five dizygous and two monozygous pairs, the type of twinning being decided on clinical criteria alone).

Parents, sibs, and children. Only proportions of affected sibs are considered since no parent can be anencephalic and very few spina bifida cystica patients have as yet had families. However, two female index patients in the multiple vertebral anomalies group each had a parent affected with the same type of defect (one mother and one father).

It should be noted that the affected relatives cannot be grouped in so sophisticated a way as the index patients, because the latter had attended for treatment over many years and many excellent radiographs were available. The diagnosis in sibs is necessarily less complete since many of them were dead and in others radiography was either incomplete or of only limited value. Thus, while index patients are in four groups (see above), sibs can only be divided into three (those with anencephaly, spinabifida cystica, or other vertebral anomalies).

The proportions of affected sibs are given in Tables I-IV and expressed as percentages in Table V.

TABLE I

PROPORTIONS OF AFFECTED SIBS OF 39 INDEX PATIENTS WITH MULTIPLE VERTEBRAL ANOMALIES INCLUDING SPINA BIFIDA CYSTICA (GROUP 1)

\begin{tabular}{l|c|c|c}
\hline \multirow{2}{*}{ Affected Sibs (including stillbirths) } & \multicolumn{3}{|c}{ Index Patients } \\
\cline { 2 - 4 } & $\begin{array}{c}\text { Males } \\
(\mathrm{n}=13)\end{array}$ & $\begin{array}{c}\text { Females } \\
(\mathrm{n}=26)\end{array}$ & $\begin{array}{c}\text { Total } \\
(\mathrm{n}=39)\end{array}$ \\
\cline { 2 - 4 } Brothers & $n=15$ & $n=24$ & $n=39$ \\
Anencephaly & - & 1 & 1 \\
Spina bifida cystica & - & - & 2 \\
Multiple vertebral anomalies & $n=6$ & $n=27$ & $n=33$ \\
\hline Sisters & - & 1 & 1 \\
Anencephaly & - & 1 & 1 \\
Spina bifida cystica & - & - & - \\
Multiple vertebral anomalies & $n=21$ & $n=51$ & $n=72$ \\
\hline Total & - & 2 & 2 \\
Anencephaly & 2 & 1 & 3 \\
Spina bifida cystica & - & - & - \\
Multiple vertebral anomalies & & & \\
\hline
\end{tabular}

+ (Details of individual kindreds are given in Wynne-Davies, 1973). 
TABLE II

PROPORTIONS OF AFFECTED SIBS OF 79 INDFX PATIENTS WITH MULTIPLE VERTEBRAL ANOMALIES INCLUDING SPINA BIFIDA OCCULTA (GROUP 2)

\begin{tabular}{l|c|c|c}
\hline \multirow{2}{*}{ Affected Sibs (including stillbirths) } & \multicolumn{3}{|c}{ Index Patients } \\
\cline { 2 - 4 } & $\begin{array}{c}\text { Males } \\
(\mathrm{n}=19)\end{array}$ & $\begin{array}{c}\text { Females } \\
(\mathrm{n}=60)\end{array}$ & $\begin{array}{c}\text { Total } \\
(\mathrm{n}=79)\end{array}$ \\
\hline $\begin{array}{l}n=21 \\
\text { Brothers }\end{array}$ & $\begin{array}{c}n=77 \\
\text { Anencephaly }\end{array}$ & $\begin{array}{c}n=98 \\
3\end{array}$ \\
Spina bifida cystica & - & 1 & 1 \\
Multiple vertebral anomalies & $n=25$ & $n=47$ & $n=72$ \\
\hline Sisters & 1 & 2 & 3 \\
Anencephaly & 1 & - & 1 \\
Spina bifida cystica & - & 1 & 1 \\
Multiple vertebral anomalies & $n=46$ & $n=124$ & $n=170$ \\
\hline Total & 1 & 5 & 6 \\
Anencephaly & 1 & 1 & 2 \\
Spina bifida cystica & - & 4 & 4 \\
Multiple vertebral anomalies & & & 3 \\
\hline
\end{tabular}

TABLE III

PROPORTIONS OF AFFECTED SIBS OF 118 INDEX PATIENTS WITH MULTIPLE VERTEBRAL ANOMALIES WITHOUT SPINA BIFIDA (GROUP 3)

\begin{tabular}{l|c|c|c}
\hline \multirow{2}{*}{ Affected Sibs (including stillbirths) } & \multicolumn{3}{|c}{ Index Patients } \\
\cline { 2 - 4 } & $\begin{array}{c}\text { Males } \\
(\mathrm{n}=28)\end{array}$ & $\begin{array}{c}\text { Females } \\
(\mathrm{n}=90)\end{array}$ & $\begin{array}{c}\text { Total } \\
(\mathrm{n}=118)\end{array}$ \\
\hline $\begin{array}{l}\text { Brothers } \\
\text { Anencephaly }\end{array}$ & $\begin{array}{c}n=41 \\
\text { Spina bifida cystica }\end{array}$ & $\begin{array}{c}n=88 \\
\mathbf{2}\end{array}$ & $\begin{array}{c}n=129 \\
1\end{array}$ \\
Multiple vertebral anomalies & - & 2 & 3 \\
\hline Sisters & $n=24$ & $n=87$ & $n=111$ \\
Anencephaly & - & - & -3 \\
Spina bifida cystica & 1 & 2 & 3 \\
Multiple vertebral anomalies & 5 & - & 5 \\
\hline Total & $n=65$ & $n=175$ & $n=240$ \\
Anencephaly & - & 1 & 1 \\
Spina bifida cystica & 5 & 2 & 7 \\
Multiple vertebral anomalies & 5 & 2 & 7 \\
\hline
\end{tabular}

TABLE IV

PROPORTIONS OF AFFECTED SIBS OF 101 INDEX PATIENTS WITH MINOR OR LOCALIZED VERTEBRAL ANOMALIES (GROUP 4)

\begin{tabular}{l|c|c|c}
\hline \multirow{2}{*}{ Affected Sibs (including stillbirths) } & \multicolumn{3}{|c}{ Index Patients } \\
\cline { 2 - 4 } & $\begin{array}{c}\text { Males } \\
(\mathrm{n}=41)\end{array}$ & $\begin{array}{c}\text { Females } \\
(\mathrm{n}=60)\end{array}$ & $\begin{array}{c}\text { Total } \\
(\mathrm{n}=101)\end{array}$ \\
\hline $\begin{array}{l}\text { Brothers } \\
\text { Anencephaly }\end{array}$ & - & $n=75$ & $n=133$ \\
Spina bifida cystica & - & - & - \\
Multiple vertebral anomalies & - & - & - \\
\hline Sisters & $n=41$ & $n=71$ & $n=112$ \\
Anencephaly & - & - & - \\
Spina bifida cystica & - & - & - \\
Multiple vertebral anomalies & - & - & - \\
\hline Total & $n=99$ & $n=146$ & $n=245$ \\
Anencephaly & - & - & - \\
Spina bifida cystica & - & 1 & - \\
Multiple vertebral anomalies & - & - & - \\
\hline
\end{tabular}

TABLE V

PERCENTAGE PROPORTIONS OF AFFECTED SIBS

\begin{tabular}{|c|c|c|c|c|}
\hline \multirow{2}{*}{$\begin{array}{l}\text { Affected Sibs } \\
\text { (including stillbirths) }\end{array}$} & \multicolumn{4}{|c|}{ Index Patients } \\
\hline & Group 1 & Group 2 & Group 3 & Group 4 \\
\hline $\begin{array}{l}\text { Edinburgh (total) } \\
\text { Anencephaly } \\
\text { Spina bifida cystica } \\
\text { Multiple vertebral anomalies }\end{array}$ & $\begin{array}{l}7.5 \\
2.5 \\
5.0 \\
-\end{array}$ & 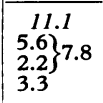 & $\begin{array}{l}7.5 \\
\begin{array}{l}1.3 \\
2.5 \\
3.8\end{array} \\
3.5\end{array}$ & $\bar{z}$ \\
\hline $\begin{array}{l}\text { London (total) } \\
\text { Anencephaly } \\
\text { Spina bifida cystica } \\
\text { Multiple vertebral anomalies }\end{array}$ & $\begin{array}{l}3.1 \\
3.1 \\
-\end{array} 6.3$ & $\frac{1.3\}_{1.3}^{2.6}}{1.3}$ & $\begin{array}{l}-5.2 \\
2.6 \\
2.6\end{array}$ & $\begin{array}{l}0.7 \\
-\int_{-}^{\prime} 0.7 \\
\end{array}$ \\
\hline $\begin{array}{l}\text { Total } \\
\text { Anencephaly } \\
\text { Spina bifida cystica } \\
\text { Multiple vertebral anomalies }\end{array}$ & $\begin{array}{l}6.9 \\
2.8 \\
4.2 \\
-\end{array} 6.9$ & $\begin{array}{l}7.1 \\
3.5 \\
1.2 \\
2.4\end{array}$ & $\begin{array}{l}5.8 \\
0.4\}^{2.9} \\
2.6 \\
3.0\end{array}$ & $\begin{array}{c}0.4 \\
0.4 \\
-\end{array}$ \\
\hline
\end{tabular}

The figures for the first three groups were much in excess of the general population frequency of 0.3 to $0.8 \%$ for anencephaly and spina bifida cystica combined and an estimated $0.1 \%$ for other vertebral defects. There was great similarity between the groups with multiple vertebral anomalies together with a neural arch defect (cystica or occulta), and the group with multiple vertebral anomalies without an apparent neural arch defect. The difference between these and the group with solitary vertebral anomalies is striking. Amongst 245 sibs of the last group there was only one with spina bifida cystica $(0.4 \%$, which is close to the general population frequency and probably coincidental).

Many index patients were adult, not severely deformed, and had children of their own-none of 59 was affected (spina bifida occulta group 20; multiple vertebral anomalies 19; solitary vertebral anomalies 20).

Second- and third-degree relatives. Only the proportions of affected half-sibs, nephews, nieces, and first cousins are noted (Table VI). These are likely to be the most reliable figures since individuals were contemporary with the index patients and medical confirmation of the diagnosis was available.

The only second-degree relatives affected were in the spina bifida occulta group $(1.3 \%)$. The proportions of affected third-degree relatives in all groups were near the estimated population frequency.

There was no relative with a Klippel Feil syndrome, and there were no significant findings relating to different clinical groupings such as upper and lower vertebral defects; those with or without a bar; Sprengel's shoulder; rib anomalies; diastematomyelia, or neurological defects. 
TABLE VI

PROPORTIONS OF AFFECTED SECOND- AND THIRD-DEGREE RELATIVES

\begin{tabular}{|c|c|c|c|c|}
\hline \multirow{2}{*}{ Affected Relatives } & \multicolumn{4}{|c|}{ Index Patients } \\
\hline & Group 1 & Group 2 & Group 3 & Group 4 \\
\hline $\begin{array}{l}\text { Second degree* } \\
\text { Anencephaly } \\
\text { Spina bifida cystica } \\
\text { Multiple vertebral } \\
\text { anomalies }\end{array}$ & $\begin{array}{c}n=14 \\
- \\
- \\
-\end{array}$ & $\begin{array}{c}n=80 \\
1(1.3 \%) \\
1(1.3 \%) \\
-\end{array}$ & $\begin{array}{c}n=146 \\
- \\
- \\
-\end{array}$ & $\begin{array}{c}n=142 \\
- \\
- \\
-\end{array}$ \\
\hline $\begin{array}{l}\text { Third degree† } \\
\text { Anencephaly } \\
\text { Spina bifida cystica } \\
\text { Multiple vertebral } \\
\text { anomalies }\end{array}$ & $\begin{array}{c}n=405 \\
1(0.2 \%) \\
1(0.2 \%) \\
-\end{array}$ & $\begin{array}{c}n=783 \\
1(0.1 \%) \\
2(0.3 \%) \\
-\end{array}$ & $\begin{array}{c}n=1461 \\
1(0.1 \%) \\
3(0.2 \%) \\
-\end{array}$ & $\begin{array}{c}n=944 \\
\overline{(0.1} \%) \\
-\end{array}$ \\
\hline
\end{tabular}

* Half sibs, nephews and nieces only.

$\dagger$ First cousins only.

Consanguinous parents. There were two instances of related parents (first cousins), both index patients were in the solitary vertebral anomalies group, one with kyphoscoliosis and the other with a simple vertebral fusion. A total of seven sibs, two sons and three daughters, were all normal as were the parents.

\section{Epidemiology-environmental factors}

Maternal obstetric and gynaecological history. Irregularities of the menstrual cycle are very common, but it was noted that nearly half the mothers of index patients in the spina bifida cystica and occulta groups had a history of irregular menstruation, long periods of infertility, menorrhagia, severe dysmenorrhoea and so on, whereas amongst the other two groups of index patients and amongst controls, rather less than one quarter of mothers had similar complaints.

The total number of previous abortions did not differ significantly from the expected figure of $15 \%$. However, when reviewed case by case, it became apparent that a large number of abortions came from very few families. In the spina bifida cystica and occulta groups, seven mothers between them had 27 abortions - over half of the total 50 . These same seven mothers between them also had two anencephalic stillbirths, four children with spina bifida and meningocele, and three other (apparently normal) stillbirths. This type of history was not so striking in the other two groups but only six of the 219 mothers had one-third of the 71 abortions recorded.

Maternal illness. The only possible significant finding under this heading related to maternal hypertension and toxaemia of pregnancy amongst mothers of both the spina bifida and the multiple vertebral anomalies groups. The diagnosis is a clinical one and it is difficult to be precise in a retrospective survey but findings were confirmed by medical evidence wherever possible. Thirteen per cent of mothers were affected compared with $7 \%$ of controls and of the localized vertebral anomalies group.

Parental age and parity. The mean ages of fathers and mothers and the mean of the paternalmaternal age difference were significantly raised for all groups, but not very markedly so. There was a significant excess of first born children amongst the spina bifida occulta and multiple vertebral anomalies groups, but not amongst those with localized vertebral anomalies (Table VII). (The figures did not reach a significant level in the spina bifida cystica group either, but numbers are small.)

Birthweight. The mean birthweight of index patients in the spina bifida and multiple vertebral anomalies groups was significantly low compared with their sibs ( $3040 \pm 590 \mathrm{~g}$, compared with $3356 \pm$ $545 \mathrm{~g})$.

TABLE VII

PARITY OF INDEX PATIENTS

\begin{tabular}{|c|c|c|c|c|c|c|c|c|}
\hline \multirow{3}{*}{ Parity } & \multicolumn{8}{|c|}{ Index Patients } \\
\hline & \multicolumn{2}{|c|}{ Group 1} & \multicolumn{2}{|c|}{ Group 2} & \multicolumn{2}{|c|}{ Group 3} & \multicolumn{2}{|c|}{ Group 4} \\
\hline & Obs & Exp & Obs & Exp & Obs & Exp & Obs & Exp \\
\hline $\begin{array}{l}\text { First born } \\
\text { Second born } \\
\text { Third born or later }\end{array}$ & $\begin{array}{l}18 \\
11 \\
10\end{array}$ & $\begin{array}{l}14.24 \\
12.19 \\
12.57\end{array}$ & $\begin{array}{l}38 \\
13 \\
28\end{array}$ & $\begin{array}{l}28.84 \\
24.68 \\
25.48\end{array}$ & $\begin{array}{l}58 \\
31 \\
29 \\
\end{array}$ & $\begin{array}{l}43.08 \\
36.87 \\
38.05\end{array}$ & $\begin{array}{l}40 \\
29 \\
32 \\
\end{array}$ & $\begin{array}{l}36.87 \\
31.56 \\
32.57 \\
\end{array}$ \\
\hline Total & \multicolumn{2}{|c|}{39} & \multicolumn{2}{|c|}{79} & \multicolumn{2}{|c|}{118} & \multicolumn{2}{|c|}{101} \\
\hline Significance & \multicolumn{2}{|c|}{ Not significant } & \multicolumn{2}{|c|}{$\begin{array}{c}\text { Highly significant } \\
0.01>\mathrm{p}>0.001\end{array}$} & \multicolumn{2}{|c|}{$\begin{array}{c}\text { Significant } \\
0.02>p>0.01\end{array}$} & \multicolumn{2}{|c|}{ Not significant } \\
\hline
\end{tabular}


TABLE VIII

SOCIAL CLASS OF 72 INDEX PATIENTS (Edinburgh City, Lothians, and Fife only)

\begin{tabular}{|c|c|c|c|c|c|c|}
\hline \multirow{3}{*}{ Social Class } & \multicolumn{6}{|c|}{ Index Patients } \\
\hline & \multicolumn{2}{|c|}{ Groups 1 and 2} & \multicolumn{2}{|c|}{ Group 3} & \multicolumn{2}{|c|}{ Group 4} \\
\hline & Obs & Exp* & Obs & Exp* & Obs & Exp* \\
\hline $\begin{array}{l}1 \text { and } 2 \\
3 \text { and } 5\end{array}$ & $\begin{array}{r}44 \\
11 \\
17\end{array}$ & $\begin{array}{r}6.10 \\
16.99 \\
8.91\end{array}$ & $\begin{array}{r}2 \\
6 \\
12\end{array}$ & $\begin{array}{r}3.81 \\
10.62 \\
5.57\end{array}$ & $\begin{array}{r}2 \\
5 \\
13\end{array}$ & $\begin{array}{r}3.81 \\
10.62 \\
5.57\end{array}$ \\
\hline Total & \multicolumn{2}{|c|}{32} & \multicolumn{2}{|c|}{20} & \multicolumn{2}{|c|}{20} \\
\hline Significance & \multicolumn{2}{|c|}{$\begin{array}{c}\text { Highly significant } \\
0.01>p>0.001\end{array}$} & \multicolumn{2}{|c|}{$\begin{array}{c}\text { Highly significant } \\
0.01>p>0.001\end{array}$} & \multicolumn{2}{|c|}{$\begin{array}{c}\text { Highly significant } \\
0.01>p>0.001\end{array}$} \\
\hline
\end{tabular}

* Expected figures calculated from Registrar General's annual reports.

Seasonal variation. There were equal numbers of births in winter and summer in all groups.

Social class. There was a highly significant proportion of index patients from the lower social classes 4 and 5 (using the Registrar General's grading of 1-5). This has previously been shown in many surveys of anencephaly and spina bifida, but the effect was quite clear in this survey for all congenital vertebral anomalies (Table VIII). Figures for 72 patients from Edinburgh City, the Lothians, and Fife only are shown since these are likely to be the most accurate. These are patients who would normally be treated in Edinburgh and results are not diluted by (probably upper social class) patients travelling long distances to come to a specialist clinic. The 'expected' figure for social classes 4 and 5 in the area was $28 \%$, whereas this survey showed $58 \%$ of index patients in this low grade.

Regional distribution. Sixty per cent of index patients came from London, the south-east, and east of England; $27 \%$ from Edinburgh, the east of Scotland, and north-east England, and only 13\% from areas of high frequency for the neural tube defects (Ireland, Wales, and western regions of Scotland). Enquiry was made as to where the parents and grandparents of index patients came from and data was available in 232 cases. Amongst those patients who came from 'high risk' areas, $89 \%$ of parents of the spina bifida and the multiple anomalies groups also came from these areas, compared with only $63 \%$ of parents of children with solitary vertebral anomalies. This was just significant at the $5 \%$ level.

\section{Discussions and conclusions}

This study has shown that multiple vertebral anomalies (with or without spina bifida occulta) should be grouped aetiologically with the neural tube malformations, spina bifida cystica, and anencephaly. The proportion of sibs affected with neural tube malformations of the index patients with multiple vertebral anomalies and spina bifida occulta, is as high as if the index patients had had spina bifida cystica or anencephaly. Where the index patients had multiple vertebral anomalies alone the proportion of sibs with spina bifida or anencephaly is rather less, but still four or five times higher than in the general population.

Amongst the 39 patients with multiple vertebral anomalies and spina bifida cystica there were no affected sibs with other types of vertebral anomaly. However, the group is small and this finding is probably not significant. It should be stressed that the figures for affected sibs with anencephaly and spina bifida cystica are likely to be accurate because these severe deformities are easily diagnosed, whereas the figures for sibs with 'other vertebral anomalies' can only be a minimum one.

Further evidence for the relationship between spina bifida and multiple vertebral anomalies is given by the epidemiological side of the survey, in which data for these same groups are similar to each other and to published work relating to spina bifida cystica and anencephaly.

Solitary hemivertebrae, localized anterior body defects, and minor anomalies appear to be separate entities; isolated, sporadic events carrying no risk to subsequent sibs. There was no excess of any neural tube defect within their families and most other data was dissimilar. The group was only alike in having a slightly raised maternal age and an excess of children from social classes 4 and 5 .

Since there were no affected relatives with the Klippel Feil syndrome, it is likely that this group of cervical vertebral anomalies is also aetiologically unrelated to the neural tube defects. 
Genetic advice and prenatal diagnosis. The risk to sibs of cases with multiple vertebral anomalies is approximately 3 to $7 \%$ for neural tube malformations and 2 to $3 \%$ for multiple vertebral anomalies alone; being higher in the Edinburgh area than in London. Aetiology is likely to be multifactorial, with both genetic and environmental factors playing a major part in the aetiology.

Now that the prenatal diagnosis of anencephaly and spina bifida cystica is becoming possible by detecting alpha-fetoproteins in the amniotic fluid (Brock and Sutcliffe, 1972), the implications of adding other congenital defects to the same aetiological group are obvious. The alpha-fetoproteins are thought to arise from free cerebrospinal fluid and would therefore be unlikely to be present in a fetus with only multiple vertebral anomalies and complete skin cover. However, these families are clearly at risk of a subsequent sib developing anencephaly or spina bifida cystica and these risks should be made known to them, since prenatal diagnosis is possible for the 'open' defects.

Similarly, in families in whom anencephaly or spina bifida cystica has already occurred, a subsequent child may present with multiple congenital vertebral defects. These anomalies are frequently not clinically apparent at birth, but there is a potential risk of serious scoliosis, kyphosis, and paraplegia developing throughout the growing period. Whole-spine radiographs taken in the neonatal period would allow early diagnosis to be made and preventive measures taken early.

Patients with multiple vertebral anomalies are usually less severely handicapped than those with spina bifida cystica and more frequently have children of their own. In this survey, no child (of a total of 59) was affected, but it is likely from Carter's and Evans's figures (1973b) for the children of patients with spina bifida cystica that there would be an increased risk of a neural tube defect presenting in the next generation, with similar implications for genetic counselling.

The index patients in this survey were all treated by Professor J. I. P. James (London 1948-58; Edinburgh 1958-68) and Mr C. W. Manning (Royal National Orthopaedic Hospital, London 1958-68) and I am most grateful to them both for access to case records and their interest in the project. A large number of people have assisted with various aspects of the survey and detailed acknowledgements are made at the end of the Thesis (Wynne-Davies, 1973).

\section{REFERENCES}

Brock, D. J. H. and Sutcliffe, R. G. (1972). Alpha-fetoprotein in the antenatal diagnosis of anencephaly and spina bifida. Lancet, 2, 197-199.

Carter, C. O., David, P. A., and Laurence, K. M. (1968). A family study of major central nervous system malformations in South Wales. Fournal of Medical Genetics, 5, 81-106.

Carter, C. O. and Evans, K. (1973a). Spina bifida and anencephalus in Greater London. Fournal of Medical Genetics, 10, 209-234.

Carter, C. O. and Evans, K. (1973b). Children of adult survivors with spina bifida cystica. Lancet, 2, 924-926.

Carter, C. O. and Fraser Roberts, J. A. (1967). The risk of recurrence after two children with central-nervous-system malformations. Lancet, 1, 306-308.

Edwards, J. H. (1958). Congenital malformations of the central nervous system in Scotland. British fournal of Preventive and Social Medicine, 12, 115-130.

Elwood, J. H. (1970). Anencephalus in Belfast, incidence and secular and seasonal variations (1950-66). British fournal of Preventive and Social Medicine, 24, 78-88.

Fedrick, J. (1970). Anencephalus: variation with maternal age, parity, social class and region in England, Scotland, and Wales. Annals of Human Genetics, 34, 31-38.

Gunderson, C. E., Greenspan, R. H., Glaser, G. H., and Lubs, H. A. (1967). The Klippel-Feil syndrome, genetic and clinical reevaluation of cervical fusion. Medicine, 46, 491-512.

James, J. I. P. (1955). Kyphoscoliosis. Fournal of Bone and foint Surgery, 37B, 414-426.

James, J. I. P. (1967). Scoliosis, ch. 8, pp. 96-136. Livingstone, Edinburgh and London.

Lorber, J. and Levick, K. (1967). Spina bifida cystica. Incidence of spina bifida occulta in parents and in controls. Archives of Disease in Childhood, 42, 171-173.

MacEwen, G. D. (1967). Congenital scoliosis with a unilateral bar. fournal of Bone and foint Surgery, 49A, 1014.

MacEwen, G. D., Winter, R. B., and Hardy, J. H. (1972). Evaluation of kidney anomalies in congenital scoliosis. Fournal of Bone and foint Surgery, 54A, 1451-1454.

Naggan, L. and MacMahon, B. (1967). Ethnic differences in the prevalence of anencephaly and spina bifida in Boston, Massachusetts. New England fournal of Medicine, 277, 1119-1123.

Record, R. G. and McKeown, T. (1950). Congenital malformations of the central nervous system. British fournal of Social Medicine, 4, 26-50.

Registrar General for Scotland (1961-68). Annual Reports 19391967. HMSO, Edinburgh.

Richards, I. D. G., McIntosh, H. T., and Sweenie, S. (1972). A genetic study of anencephaly and spina bifida in Glasgow. Developmental Medicine and Child Neurology, 14, 626-639.

Shands, A. R. and Eisberg, H. B. (1955). The incidence of scoliosis in the State of Delaware. Fournal of Bone and foint Surgery, 37A, 1243-1249.

Williamson, E. M. (1965). Incidence and family aggregation of major congenital malformations of the central nervous system. fournal of Medical Genetics, 2, 161-172.

Winter, R. B., Moe, J. H., and Eilers, V. E. (1968). Congenital scoliosis, a study of 234 patients treated and untreated. Fournal of Bone and foint Surgery, 50A, 15-47.

Winter, R. B., Moe, J. H., and Wang, J. F. (1973). Congenital kyphosis. Fournal of Bone and foint Surgery, 55A, 223-256.

Wynne-Davies, R. (1968). Familial (idiopathic) scoliosis, a family survey. Fournal of Bone and foint Surgery, 50B, 24-30.

Wynne-Davies, R. (1973). Genetic and other Factors in the Aetiology of Scoliosis, pp. 62-120. PhD Thesis, University of Edinburgh. 